\title{
Radiation defect formation processes as a method for activation of red phosphorus in the Trofimov-Gusarova Reaction
}

\author{
Boris Sukhov,* Svetlana Malysheva, Tamara Vakul'skaya, Vladislav Tirsky, Evgueni \\ Martynovich, Yurii Smetannikov, Nataliya Tarasova
}
A.E. Favorsky Irkutsk Institute of Chemistry Siberian Branch of Russian Academy of Sciences, 1 Favorsky St., Irkutsk, 664033 Russian Federation
E-mail: sukhov@irioch.irk.ru

\section{This paper is dedicated to Professor Boris Trofimov on the occasion of his $65^{\text {th }}$ birthday}

(received 29 May 03; accepted 09 Oct 03; published on the web 17 Oct 03)

\begin{abstract}
A new approach is discussed for modifying the reactivity of elemental phosphorus by controlled defect formation in its structure, and the application of this methodology in the synthesis of organophosphorus compounds.
\end{abstract}

Keywords: Elemental phosphorus, activation, defect formation, biographic defects, induced defects

\section{Introduction}

The phosphorylation of organic compounds with elemental phosphorus is a very convenient approach to $\mathrm{C}-\mathrm{P}$ bond formation and the synthesis of phosphines and phosphine oxides. These key organophosphorus compounds, which have been used widely for the design of efficient ligands for a new generation of catalysts, including those for enantioselective processes, ${ }^{1-4}$ flame retardants, ${ }^{5}$ agents for extraction of rare earth and transuranic elements, ${ }^{6}$ and building blocks and starting materials for the preparation of biologically active compounds for medicine and agriculture. $^{7-12}$ However, until recently, the studies concerning direct reactions of elemental phosphorus with organic compounds have not been efficient and systematic enough to produce any significant results, mainly because strong and technologically complex conditions (high temperature and pressure, the necessity of using expensive activators, etc. $)^{13-17}$ were required for the activation of elemental phosphorus.

A new method for the activation of elemental phosphorus in heterogeneous highly basic media, developed in the late 1980 s by B. Trofimov and N. Gusarova with co-workers, ${ }^{18-23}$ represented a new approach to $\mathrm{C}-\mathrm{P}$ bond formation, which makes possible the direct 
phosphorylation of organic halides, dihaloalkanes, electrophilic alkenes, acetylenes and oxiranes with elemental phosphorus, and the preparation of primary, secondary and tertiary phosphines and phosphine oxides, including functionalized and unsaturated ones. ${ }^{24-27}$

This paper discusses new prospects for further development of the Trofimov-Gusarova reaction, which involve successful application of ionizing radiation (electromagnetic radiation in the X-ray and $\gamma$-ranges) for activation of elemental phosphorus and modifying its reactivity by means of controlled defect formation in its structure. ${ }^{28-31}$ In solid-state physics and chemistry, the term "defect" (which is generally related to the anomaly of the phenomenon) assumes the meaning of a structural element which is different from the remaining regular portion of the substance and possesses specific local properties. ${ }^{32}$ There are two main types of defects, induced defects that appear in solid samples owing to an external effect, and biographical defects associated with a particular procedure for the preparation of solid compounds. ${ }^{32}$

\section{Results and Discussion}

A study concerning the possibility of activation of ordinary commercial red phosphorus by induced radiation defect formation has for the first time revealed an effect of double magnetic transfer in red phosphorus, caused by X-ray irradiation. ${ }^{33}$

Commercial red phosphorus is paramagnetic and gives rise to an ESR signal caused by biographical defects, which obviously represent spatially distributed lone electrons not participating in formation of $\mathrm{P}-\mathrm{P}$ bonds in the phosphorus polymer. After X-ray irradiation, this paramagnetic red phosphorus becomes diamagnetic. Irradiated red phosphorus at room temperature shows no ESR signal, at least for several hours; then, after 10 hours, the ESR signal builds up again, and its intensity twice exceeds that of the initial non-irradiated red phosphorus.

The fact that irradiated red phosphorus loses its paramagnetic properties may be accounted for by redistribution of lone electrons in biographical defects under the action of high-energy quanta to produce spatially separated non-paramagnetic anionic and cationic defects. The increase of the ESR signal's intensity over the course of time may be associated with a relaxation process, constituting transformation of the high-energy polymeric system of red phosphorus, containing both positive and negative charges, into a more stable uncharged radical state. The subsequent two-fold increase of the ESR signal's intensity for irradiated red phosphorus may, in turn, be explained by contribution of additional anionic and cationic defects, formed upon radiation dissociation of chemical bonds in phosphorus polymer, to the relaxation process.

It is remarkable that the duration of the relaxation process decreases rapidly upon raising the temperature, thus indicating the thermo-activating character of this process and its relatively low activation energy.

The induced radiation defect formation was first employed for activation of ordinary commercial red phosphorus in the process of phenylacetylene phosphorylation. ${ }^{30}$ Ordinary red phosphorus is known to react with phenylacetylene in the superbase system KOH-DMSO upon 
moderate heating to give a mixture of Z,Z,Z-tri-styrylphosphine 1 and E,Z,Z-tri-styrylphosphine 2 isomers in low yield, along with the Z,Z,Z-tri-styrylphosphine oxide 3. X-Ray irradiation of the same

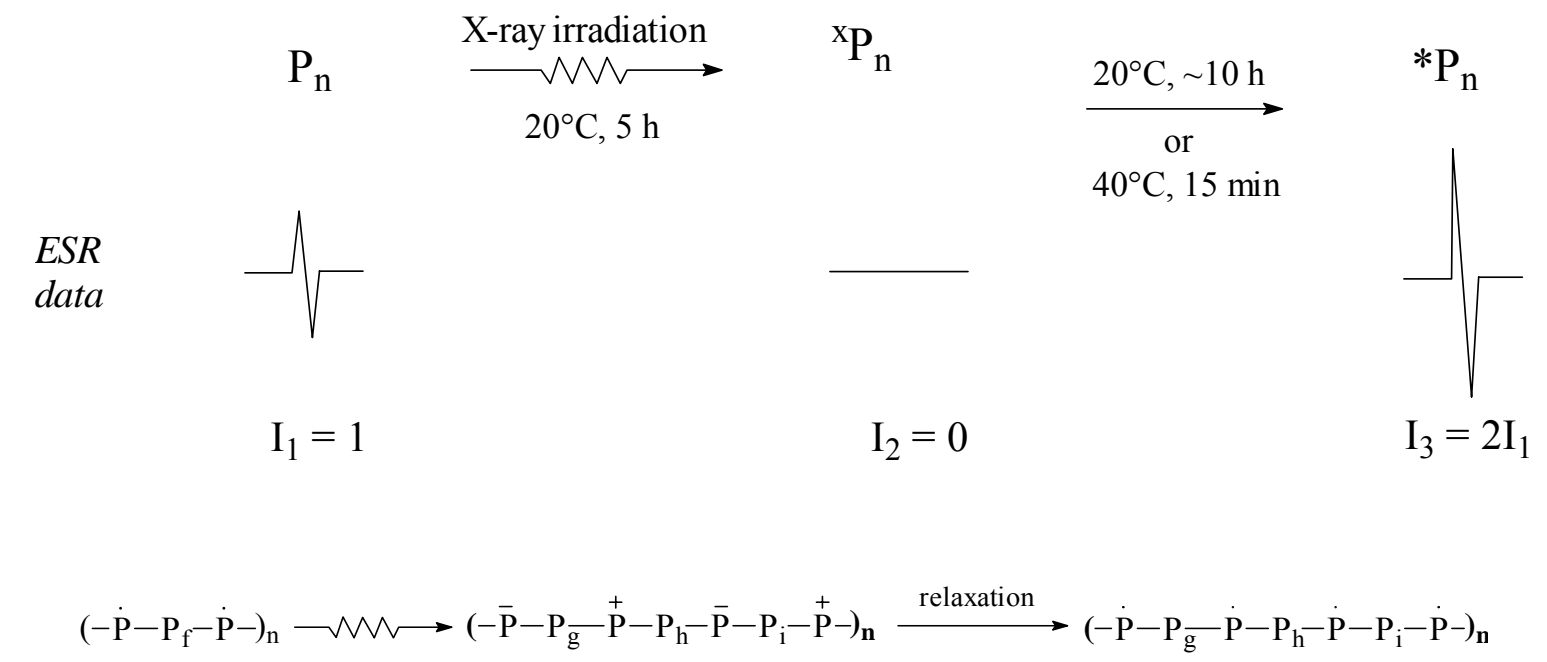

red phosphorus results in a drastic change in its reactivity: under comparable conditions, when phosphorus is used in the phase of non-paramagnetic ionic defects, the total yield of phenylacetylene phosphorylation products is six times higher. The yield of tri-styrylphosphine isomers 1, 2 increases by three times, and no tri-styrylphosphine oxide is formed at all. The major product of the reaction is a valuable organophosphorus polymer, whose element composition and chemical properties correspond to polystyrylphosphonic acid $\mathbf{4}$.
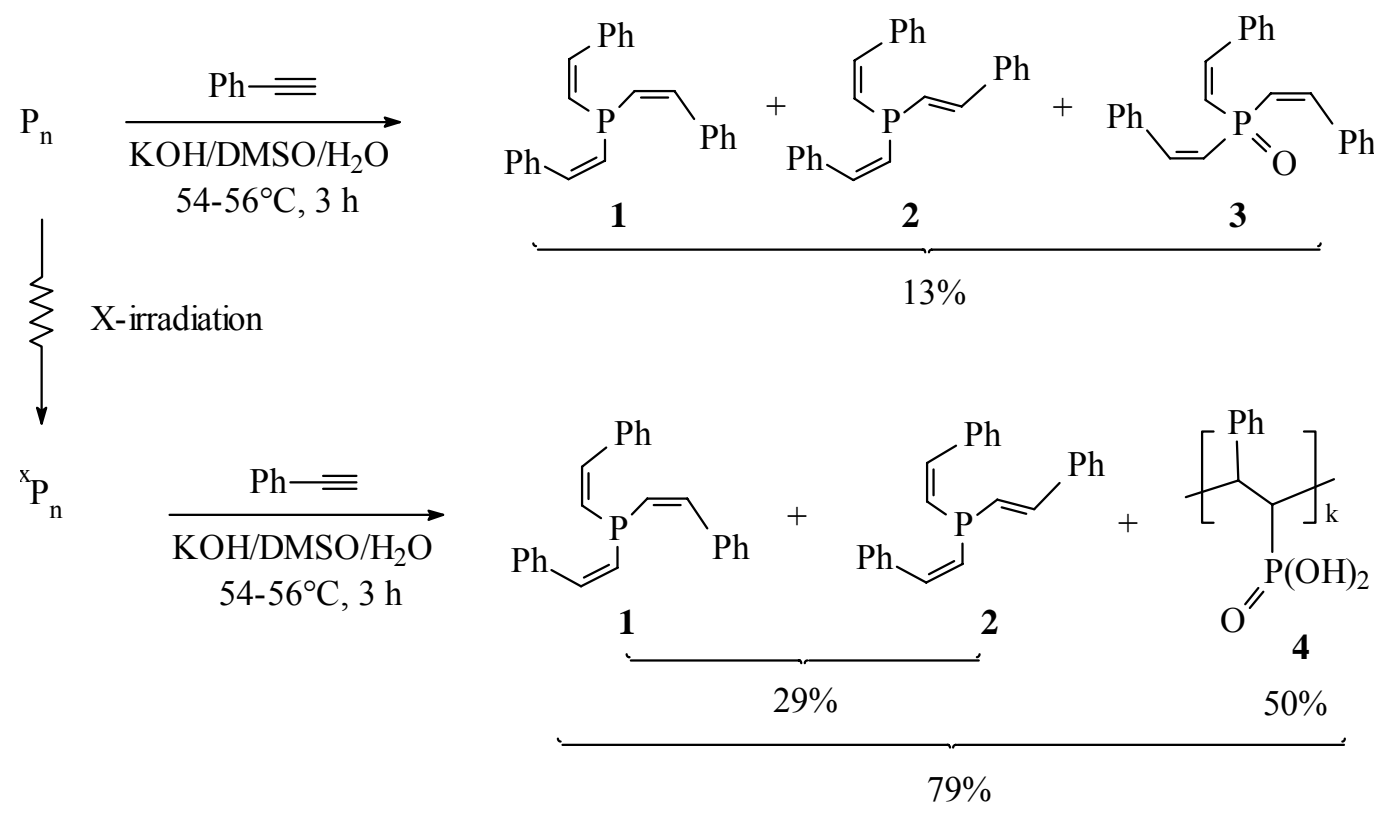
The other red phosphorus types: ${ }^{1} \mathrm{P}_{\mathrm{n}}$ (prepared by radiation thermal polymerization of white phosphorus in the presence of graphite) and ${ }^{2} \mathrm{P}_{\mathrm{n}}$ (synthesized by radiation polymerization of white phosphorus dissolved in benzene) contain biographical defects (IR, X-ray, electron- and ESR spectroscopic data). ${ }^{33}$ These defects represent local distortions in the alternation of P-P-P bonds in phosphorus polymer owing to the presence of bonds $\mathrm{P}-\mathrm{P}-\mathrm{R}$, where $\mathrm{R}$ is a graphite fragment (in the case of ${ }^{1} \mathrm{P}_{\mathrm{n}}$ ) or benzene (in the case of ${ }^{2} \mathrm{P}_{\mathrm{n}}$ ). On the example of the direct phosphorylation of allyl bromide, aryl- and hetarylalkenes and acetylene, we have obtained new information concerning the effect of biographical defects on the reactivity of elemental phosphorus.

Red phosphorus ${ }^{2} \mathrm{P}_{\mathrm{n}}$ was found to react with allyl bromide at room temperature in the system $60 \%$ aqueous $\mathrm{KOH}$-dioxane to give mainly the kinetic products, tri-(propen-2-yl)phosphine oxide 5 and (E-propen-1-yl)-(Z-propenyl)-(propen-2-yl)phosphine oxide 6 in $4: 1$ ratio in 39\% yield, the phosphorus conversion being $100 \%$. Under analogous conditions, the efficiency of allyl bromide phosphorylation with ordinary red phosphorus is 13 times lower: the yield of phosphine oxides 5 and $\mathbf{6}$ was just 3\% (18\% conversion of $\left.\mathrm{P}_{\mathrm{n}}\right)$. Complete conversion of the latter also supports the higher activity of ${ }^{2} \mathrm{P}_{\mathrm{n}}$.

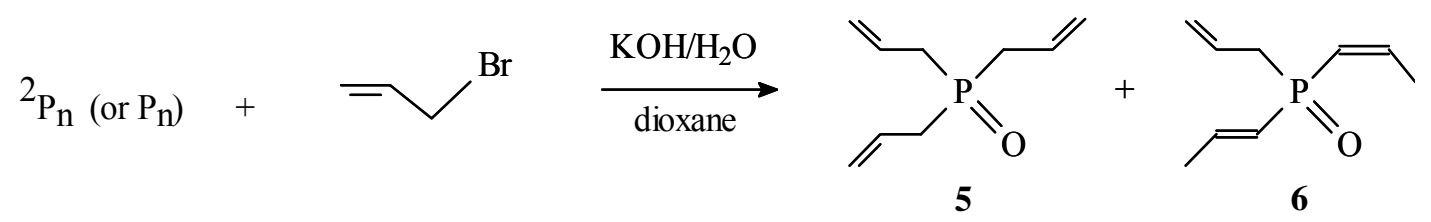

The presence of a large amount of potassium hypophosphite in the reaction mixture indicates that this activated phosphorus intensively undergoes redox processes with aqueous alkali to give, along with phosphide and phosphinite anions of type $[>\mathrm{P}]^{-}$and $[>\mathrm{P}=\mathrm{O}]^{-}{ }^{24-27}$ stable oxygencontaining acid anions which are inactive towards allyl bromide in the reaction of nucleophilic substitution. Previously, ${ }^{34}$ white phosphorus, $\mathrm{P}_{4}$, was shown to be even more active under the same conditions: the reaction resulted in the expected phosphine oxide $\mathbf{5}$ as a main product, and also products of its prototropic isomerization: bis-(propen-2-yl)(E-propen-1-yl)phosphine oxide 7 and bis-(E-propen-1-yl)(propen-2-yl)phosphine oxide 8, in a total yield of $96 \%$.

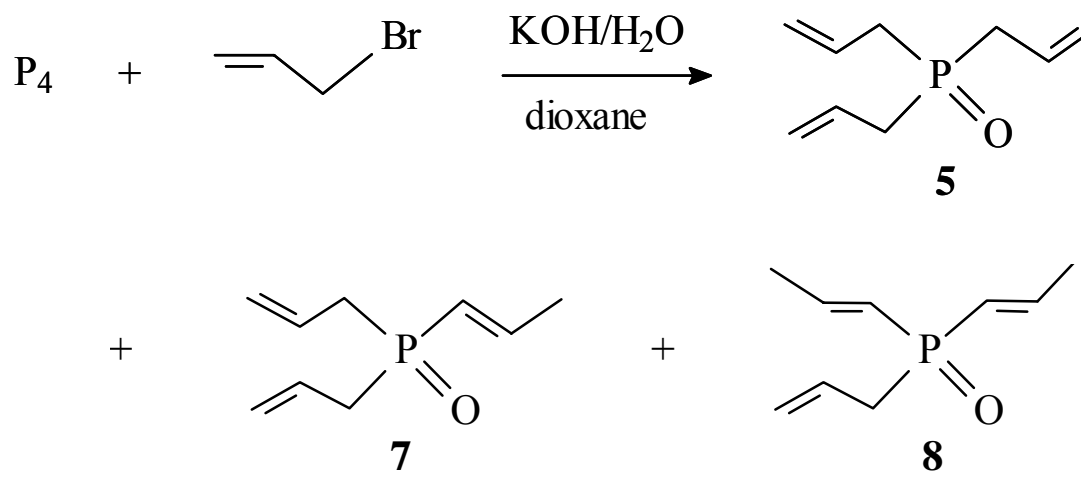


Reaction of biographical-defect-containing red phosphorus ${ }^{2} \mathrm{P}_{\mathrm{n}}$ with styrene also proceeds at room temperature to afford bis-(2-phenylethyl)phosphine oxide $\mathbf{9}$ and 2-phenylethylphosphinic acid $\mathbf{1 0}$ in $15 \%$ total yield. $^{35}$

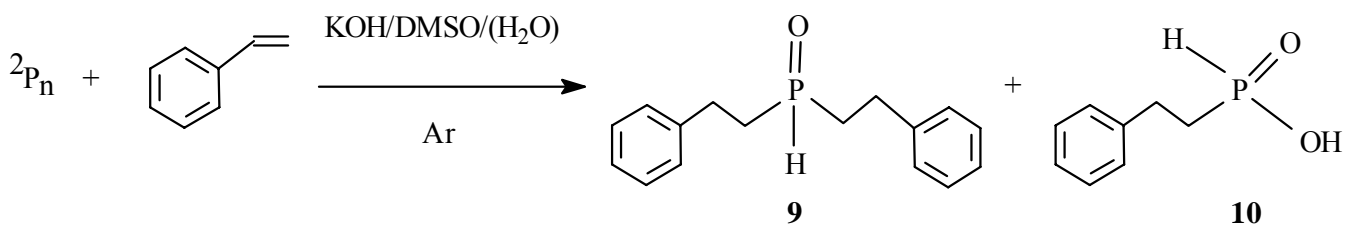

When the ordinary commercial red phosphorus, $\mathrm{P}_{\mathrm{n}}$, is used in this reaction, the yield of organophosphorus compounds 9 and 10 does not exceed 2\%. Under the same conditions, white phosphorus shows the highest activity: the total yield of compounds $\mathbf{9}$ and $\mathbf{1 0}$ is as high as $30 \%$. At the same time, in phosphorylation of 2-vinylnaphthalene $\left(90-96^{\circ} \mathrm{C}\right)$, the defect-containing ${ }^{2} \mathrm{P}_{\mathrm{n}}$ outperforms both $\mathrm{P}_{\mathrm{n}}$ and $\mathrm{P}_{4}$. The major products of this reaction in the case of ${ }^{2} \mathrm{P}_{\mathrm{n}}$ are tris-[2-(2naphthyl)ethyl]phosphine oxide 11, 2-(2-naphthyl)ethylphosphinic acid 12 and bis-[2-(2naphthyl)ethyl]phosphine oxide 13 in 1.6:1.2:1 ratio, their total yield being $73 \%$.
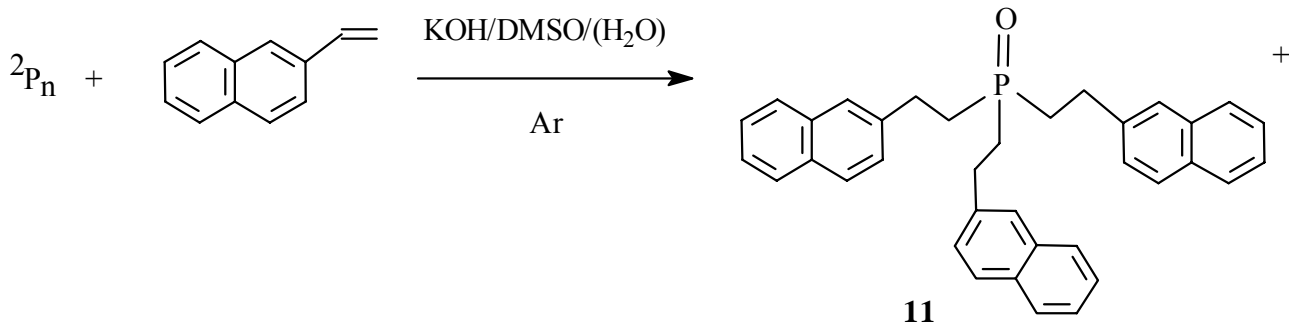

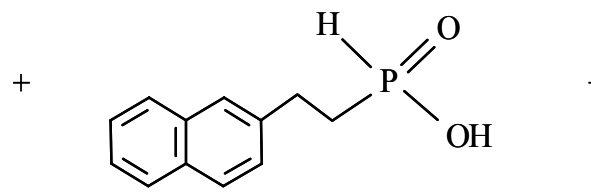

12<smiles>O=[PH](CCc1ccc2ccccc2c1)CCc1ccc2ccccc2c1</smiles>

13

Under similar conditions, phosphorylation of 2-vinylnaphthalene with $\mathrm{P}_{4}$ or $\mathrm{P}_{\mathrm{n}}$ is less efficient but more selective. The major product is the phosphine oxide $\mathbf{1 1}(58 \%$ and $44 \%$ yield, respectively). When $\mathrm{P}_{\mathrm{n}}$ is used, the acid 12 is also formed in $11 \%$ yield.

Samples of the defect-containing red phosphorus ${ }^{2} \mathrm{P}_{\mathrm{n}}$, as well as white phosphorus, have been shown to react easily at room temperature with vinylpyridines in the suspension $\mathrm{KOH}-\mathrm{DMSO}$, containing small amounts of water, to form tris-[2-(2-pyridyl)ethyl]phosphine oxide $\mathbf{1 4}$ and tris[2-(4-pyridyl)ethyl]phosphine oxide 15, respectively. ${ }^{29}$ 

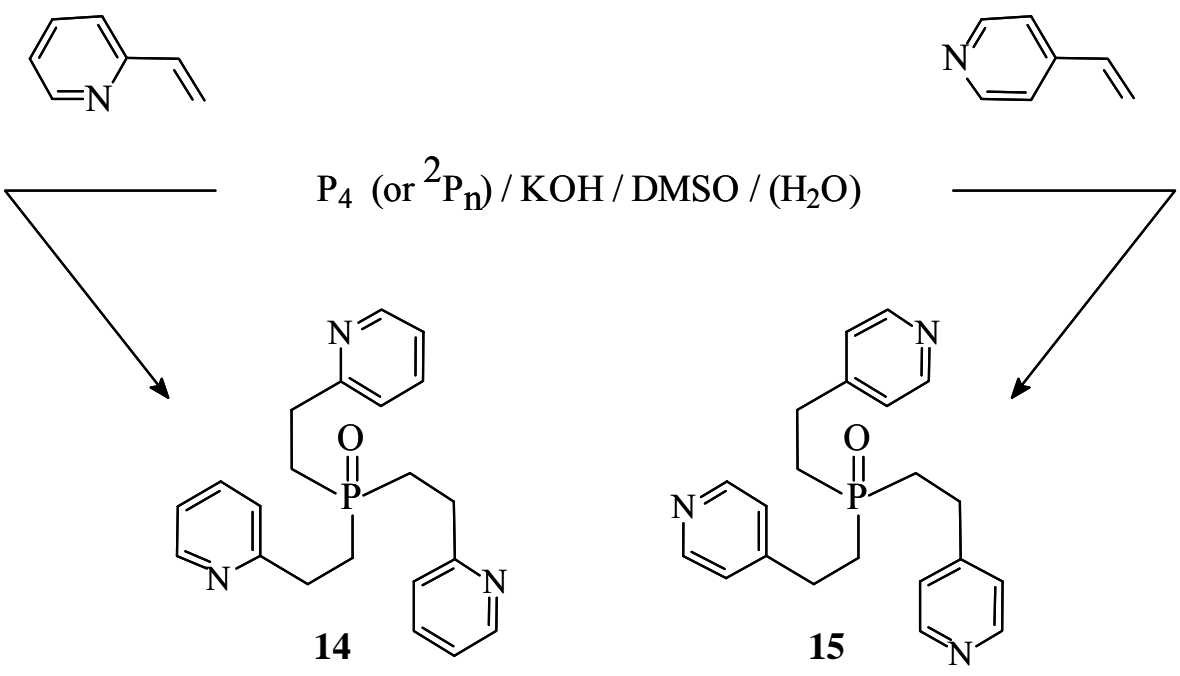

The reactivities of white phosphorus and activated red phosphorus in reaction with 4vinylpyridine are similar: the yield of phosphine oxide $\mathbf{1 5}$ is in the range of 51-58\%, while the phosphorus conversion is $90-100 \%$. At the same time, reacting white phosphorus with 2vinylpyridine proves to be more efficient: the phosphine oxide 14 is formed in $72 \%$ yield, whereas with activated red phosphorus ${ }^{2} \mathrm{P}_{\mathrm{n}}$, the yield is just $48 \%$.

Under comparable conditions, the efficiency of ordinary commercial red phosphorus in the reaction with vinylpyridines is low: the yield of phosphine oxides 14, 15 does not exceed $10 \%$, the phosphorus conversion being $28-55 \%{ }^{29}$

Phosphorylation of phenylacetylene with activated red phosphorus ${ }^{2} \mathrm{P}_{\mathrm{n}}$ or white phosphorus proceeds in the system $\mathrm{KOH}-\mathrm{DMSO}$ at room temperature and results in stereoselective formation of phosphine 1 and phosphine oxide 3 in $49 \%$ and $15 \%$ yields (when ${ }^{1} \mathrm{P}_{\mathrm{n}}$ is used), or in $48 \%$ and $10 \%$ yield, respectively (when $\mathrm{P}_{4}$ is used). ${ }^{31}$
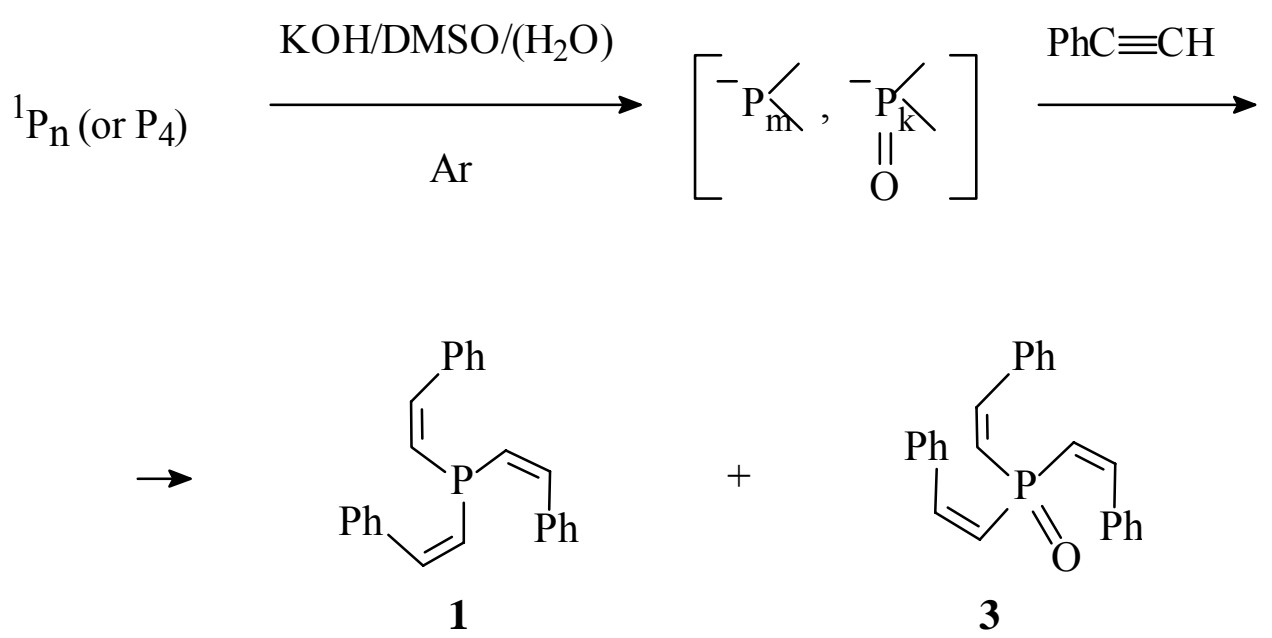
The stereoselectivity of the reaction is in accordance with the rule of trans-nucleophilic addition of phosphide and phosphinite anions, generated from elemental phosphorus molecules, to the triple bond. ${ }^{25-27}$ Under comparable conditions, the efficiency of ordinary red phosphorus in the reaction with phenylacetylene is significantly lower: the total yield of products $\mathbf{1}, \mathbf{3}$ is $5 \%{ }^{31}$

Thus, as shown above, the induced and biographical defect formation in red phosphorus allows one to obtain activated red phosphorus, which, like white phosphorus, shows high reactivity in the synthesis of organophosphorus compounds, but is free of the disadvantages of the latter (pyrophoricity and high toxicity).

To conclude, the present investigation led to the preparation of the first representatives of organophosphorus compounds possessing the properties of non-linear optical materials, which become pronounced, in particular, upon generation of the second harmonic of the neodymium laser, as well as the properties of novel organophosphorus luminophores, which can be used for the preparation of various metal complexes-scintillators with predefined characteristics. ${ }^{33}$

\section{Acknowledgements}

Financial support from the Ministry of Industry, Science and Technologies of Russian Federation (Grant No. NSH-2241.2003.3) and the Russian Foundation for Basic Research (Grant No. 02-0332648 ) is gratefully acknowledged.

\section{References}

1. Verspui, G.; Schanscema, F.; Sheldon, R. Angew. Chem. 2000, 112, 825.

2. Arisawa, M.; Yamaguchi, M. Adv. Synth. Catal. 2001, 343, 27.

3. Kuhn, N.; Göhner, M.; Steimann, M. Z. Naturforsch., B Chem. Sci. 2001, 59, 95.

4. Dodge, T.; Curtis, M.A.; Russell, M.; Sabat, M.; Finn, M.G.; Grimes, R.N. J. Am. Chem. Soc. 2000, 122, 0573.

5. Khalturinsky, N.A.; Popova, T. V.; Berlin, A.A. Usp. Khim. 1984, 53, 326.

6. Korovin, V.Yu.; Randarevich, S.B.; Bodaratsky, S.V.; Trachevsky, V.V. Zh. Neorg. Khim. 1990, 35, 2404.

7. Yudelevich, V.I.; Komarov, E.V.; Ionin, B.I. Khim.-Farm. Zh. 1985, 668.

8. Mel'nikov, N.N. Pesticidy. Khimia, Tekhnologia i Primenenie. Moscow: Nauka, 1987, 711 pp. (in Russian).

9. Gololobov, Yu.G.; Kasukhin, L. F.; Pesotskaya, G.V.; Petrenko, V. S.; Kim, T.V.; Ivanova, Zh. M. Zh. Obshch. Khim. 1978, 48, 1974.

10. Gusarova, N.K.; Kuznetsova, E.E.; Arbuzova, S.N.; Shaikhudinova, S.I.; Malysheva, S.F.; Kozlova, G.V.; Zorina, E.F.; Trofimov, B.A. Khim.-Farm. Zh. 1994, 9, 37. 
11. Gusarova, N.K.; Kuznetsova, E.E.; Shaikhudinova, S.I.; Dmitriev, V.I.; Malysheva, S.F.; Kozlova, G.V.; Trofimov, B.A. Khim.-Farm. Zh. 1996, 7, 36.

12. Malysheva, S.F.; Kuznetsova, E.E.; Belogorlova, N.A.; Kozlova, G.V.; Rakhmatulina, T.N.; Al'pert, M.L.; Gusarova, N.K.; Trofimov, B.A. Khim.-Farm. Zh. 1998, 11, 24.

13. Kosolapoff, G.M.; Maier, L. Organic Phosphorus Compounds, Vol. 1; Wiley-Interscience: New York, 1972, pp 545.

14. Kosolapoff, G.M.; Maier, L. Organic Phosphorus Compounds, Vol. 1; Wiley-Interscience: New York, 1972, pp 500.

15. Rauhut, M.M. Topics in Phosphorus Chemistry, Vol. 1; Wiley-Interscience: New York, 1964, pp 1-16.

16. Feshchenko, N.G. In: Uspekhi Khimii Fosfororganicheskikh i Seroorganicheskikh Soedinenii Kirsanov, A.V., Eds.; Naukova Dumka: Kiev, 1970, p 89.

17. Brown, C.; Hudson, R.E.; Wartew, G.A. Phosphorus Sulfur Silicon Relat. Elem. 1978, 5, 67.

18. Trofimov, B.A.; Gusarova, N.K.; Malysheva, S.F.; Vyalykh, E.P.; Rakhmatulina, T.N.; Voronkov, M.G. Izv. Akad. Nauk SSSR, Ser. Khim. 1988, 1449.

19. Trofimov, B.A.; Gusarova, N.K.; Malysheva, S.F.; Dmitriev, V.I.; Shaikhudinova, S.I.; Rakhmatulina, T.N. Zh. Org. Khim. 1989, 25, 1563.

20. Gusarova, N.K.; Trofimov, B.A.; Malysheva, S.F.; Rakhmatulina, T.N.; Vyalykh, E.P.; Voronkov, M.G. Izv. Akad. Nauk SSSR, Ser. Khim. 1989, 488.

21. Malysheva, S.F.; Gusarova, N.K.; Rakhmatulina, T.N.; Kazantseva, T.I.; Dmitriev, V.I.; Trofimov, B.A.; Izv. Akad. Nauk SSSR, Ser. Khim. 1989, 1705.

22. Gusarova, N.K.; Trofimov, B.A.; Malysheva, S.F.; Rakhmatulina, T.N.; Voronkov, M.G. Dokl. Akad. Nauk SSSR 1989, 305, 355.

23. Trofimov, B.A. Zh. Org. Khim. 1995, 31, 1368.

24. Trofimov, B.A.; Rakhmatulina, T.N.; Gusarova, N.K.; Malysheva, S.F. Usp. Khim. 1991, $60,2619$.

25. Gusarova, N.K.; Brandsma, L.; Arbuzova, S.N.; Malysheva, S.F.; Trofimov, B.A. Zh. Org. Khim. 1996, 32, 269.

26. Trofimov, B.A.; Gusarova, N.K.; Brandsma, L. Main Group Chem. News 1996, 4, 18.

27. Gusarova, N.K.; Malysheva, S.F.; Arbuzova, S.N.; Trofimov, B.A. Izv. Akad. Nauk, Ser. Khim. 1998, 1695.

28. Gusarova, N.K.; Smetannikov, Yu.V.; Sukhov, B.G.; Malysheva, S.F.; Tarasova, N.P.; Trofimov, B.A. Zh. Obshch. Khim. 2001, 71, 688.

29. Gusarova, N.K.; Shaikhudinova, S.I.; Kazantseva, T.I.; Sukhov, B.G.; Dmitriev, V.I.; Sinegovskaya, L.M.; Smetannikov, Yu.V.; Tarasova, N.P.; Trofimov, B.A. Khim. Geterotsikl. Soedin. 2001, 628.

30. Trofimov, B.A.; Sukhov, B. G.; Gusarova, N.K.; Malysheva, S.F.; Tirskii, V.V.; Ruzhnikov, L.I.; Martynovich, E.F. Dokl. Akad. Nauk. 2002, 382, 214.

31. Gusarova, N.K.; Sukhov, B.G.; Malysheva, S.F.; Kazantseva, T.I.; Smetannikov, Yu.V.; Tarasova, N.P.; Trofimov, B.A. Zh. Obshch. Khim. 2001, 71, 768. 
32. Kovtunenko, P.V. Fizicheskaya Khimiya Tverdogo Tela. Kristally s Defektami [Physical Chemistry of Solid-State Materials. Defect Crystals], Vysshaya Shkola, Moscow, 1993, p 352, (in Russian).

33. Sukhov, B.G. Ph.D. (Chem.) Thesis, A.E. Favorsky Irkutsk Institute of Chemistry, Siberian Branch of the Russian Academy of Sciences, Irkutsk, 2002, p 129 (in Russian).

34. Malysheva, S.F.; Sukhov, B.G.; Gusarova, N.K.; Shaikhudinova, S.I.; Kazantseva, T.I.; Belogorlova, N.A.; Kuimov, V.A.; Trofimov, B.A. Phosphorus, Sulfur and Silicon 2003, 175, 3, 163.

35. Gusarova, N.K.; Shaikhudinova, S.I.; Sukhov, B.G.; Kazantseva, T.I.; Malysheva, S.F.; Smetannikov, Yu.V.; Tarasova, N.P.; Kuimov, V.A.; Trofimov, B.A. Izv. Akad. Nauk., Ser. Khim. 2003, 438. 